\title{
Associations of Personality with Body Mass Index and Obesity in a Large Late Midlife Community Sample
}

\author{
Cathrine Lawaetz Wimmelmann ${ }^{a, b}$ Rikke Lund ${ }^{a}, b$ \\ Trine Flensborg-Madsen ${ }^{a, b} \quad$ Ulla Christensen ${ }^{a, b} \quad$ Merete Osler $^{a, c, d}$ \\ Erik Lykke Mortensen ${ }^{a, b}$ \\ a Department of Public Health, University of Copenhagen, Copenhagen, Denmark; \\ ${ }^{b}$ Center for Healthy Aging, Faculty of Health and Medical Sciences, University of \\ Copenhagen, Copenhagen, Denmark; ' Research Center for Prevention and Health, \\ Glostrup Hospital, Glostrup, Denmark; dDanish Aging Research Center, Universities of \\ Aarhus, Southern Denmark and Copenhagen, Copenhagen, Denmark
}

\section{Keywords}

Personality · Body mass index · Obesity · Midlife · NEO Five Factor Inventory · NEO FFI

\begin{abstract}
Objective: The study examined cross-sectional associations of personality with BMI and obesity among men and women in a large late midlife community sample. Methods: The sample comprised 5,286 Danish individuals aged 49-63 years from the Copenhagen Ageing and Midlife Biobank (CAMB) with complete information on measured BMI, personality assessed by the NEO Five Factor Inventory (NEO FFI), and sociodemographic factors including sex, age and educational length. Analysis of variance and logistic regression models were used to investigate associations between personality and $\mathrm{BMI}$ as well as obesity. Personality traits were analyzed separately and combined in the same model. Results: All personality traits except for neuroticism were significantly associated with BMI, with extraversion ( $p$ value ranged from $<0.001$ to 0.012 ) and agreeableness ( $p$ value ranged from 0.001 to 0.002 ) being the most consistent predictors of $\mathrm{BMI}$ among men and women, respectively. Furthermore, extraversion among men (high scores) $(p=0.016)$ and agreeableness among women (low scores) $(p=$ 0.026 ) were the only personality traits significantly associated with obesity when adjusting for duration of education. Conclusion: Personality was significantly associated with $\mathrm{BMI}$ and to a lesser extent with obesity, and these associations differed between men and women. Also, it was suggested that the interrelations of the five personality traits should be considered in future research of personality and health outcomes.

(C) 2018 The Author(s)

Published by S. Karger GmbH, Freiburg
\end{abstract}

Dr. Cathrine Lawaetz Wimmelmann

Department of Public Health, Unit of Medical Psychology

University of Copenhagen

Øster Farimagsgade 5A, Building 5, 1. Floor, 1353 Copenhagen K, Denmark

calw@sund.ku.dk 
Wimmelmann et al.: Associations of Personality with Body Mass Index and Obesity in a Large Late Midlife Community Sample

\section{Introduction}

Obesity defined as a BMI of $\geq 30 \mathrm{~kg} / \mathrm{m}^{2}$ is a major public health problem associated with an elevated risk of developing a wide range of comorbidities such as type 2 diabetes, cardiovascular disease, and cancer [1]. An alarming increase in the prevalence of obesity has been reported during the last decades with more than half a billion adults worldwide classified as obese in 2014 [2]. Furthermore, it has been estimated that 3.4 million individuals die of obesity-related causes each year [3]. Today, more than $47 \%$ of the Danish adult population is overweight with a BMI $\geq 25 \mathrm{~kg} / \mathrm{m}^{2}$, and more than $13 \%$ are categorized as obese. Furthermore, there is evidence that the prevalence of overweight and obesity peaks in midlife men and women aged 50-60 years [4].

While social, psychosocial, demographic, and genetic factors may be important determinants of general trends in the prevalence of overweight and obesity, they may not necessarily explain all of the substantial individual differences in BMI and weight, which can be observed in most populations. Upstream factors such as personality traits describe individual differences in stable behavioral dispositions, and during the last decades there has been a growing interest in investigating the influence of personality on health and aging [5]. This reflects the growing body of research suggesting that psychological characteristics and dispositions such as personality traits may affect health through individual factors including health-related behaviors and differences in the ability to cope with stressful experiences [5]. For instance, disordered eating may reflect a way of regulating emotions [6], while self-discipline and motivation is required to engage in regular physical activity [7]. Thus, in addition to genetic, demographic, psychosocial and social factors, weight may be substantially influenced by individual psychological dispositions including typical ways of thinking, feeling, and behaving. Most current research considers such psychological dispositions as relatively stable across adulthood emphasizing the predicting role of personality for health [8]. However, the relation is complex and may also involve inverse causality where health factors such as obesity may affect individual ways of experiencing and acting.

During the last 25 years, the most widely used model of personality structure has been the big five model, [9] which includes five broad traits: neuroticism, extraversion, openness, agreeableness, and conscientiousness. Among these traits, the most studied personality dimension in health research is neuroticism, and there is robust evidence of associations between this personality dimension and a wide range of both mental and physical health problems including depression, anxiety, eating disorders, cardiovascular disease, and type 2 diabetes [10]. In addition, several studies have observed elevated scores of neuroticism in individuals with obesity from the general population $[8,11,12]$, suggesting a positive association between neuroticism and BMI. In addition, both obese and underweight individuals tend to report more psychiatric symptoms than normal-weight individuals [13], indicating that these weight groups may score higher on neuroticism [10]. A recent cross-sectional study [12] investigated associations of personality [14] and BMI in a diverse community sample of 5,150 individuals aged 18-91 years (mean age 45 years). They reported that high neuroticism was related to a higher BMI and risk of obesity while especially conscientiousness but also extraversion and openness appeared to be important protective factors. In general, correlations were stronger for women and older individuals, emphasizing the importance of studying the effect of personality on weight in the midlife and elderly population [14].

Some studies have suggested that the personality domain of conscientiousness, comprising sub-facets such as self-discipline and order, is a protective factor for overweight and obesity $[11,12,15,16]$ presumably reflecting more health-promoting behaviors of individuals high on conscientiousness [17]. For instance, studies have reported that individuals high on conscientiousness are more physically active [18] and that they are less likely to 
Wimmelmann et al.: Associations of Personality with Body Mass Index and Obesity in a Large Late Midlife Community Sample

overeat [19] and to report disordered eating [20] than individuals low on this dimension. In fact, behavioral factors have been reported to account for $50 \%$ of the association of neuroticism with BMI and conscientiousness [12]. Thus, health-related behaviors such as diet, physical activity, alcohol consumption, and smoking are important to include in investigations of personality and BMI as they to some extent may mediate the association of personality with BMI.

Evidence of associations between the three remaining personality traits - extraversion, openness and agreeableness - is less consistent. Some studies suggest that higher extraversion is associated with a higher BMI $[8,21]$, while others have reported no association with BMI [15, 22, 23]. Yet, some studies report a negative association between extraversion and BMI in women only [12] and others a positive association in men and no associations between this personality dimension and BMI in women [16,24]. Agreeableness has been both positively [23] and negatively [24] associated with BMI in men. Finally, some studies do not find significant associations between openness and BMI $[15,23]$ while others have reported that high openness score was related to lower BMI [24].

Although, a relatively large body of research has investigated the psychological correlates of overweight and obesity, results are inconsistent, and the association of personality with weight status remains unclear. Thus, further research on the association of personality with BMI in community samples is highly needed especially in samples including individuals aged 50-60 years as the largest increase in the prevalence of overweight and obesity in Denmark has been observed in this age group [25] and there is some evidence that associations of personality with weight status are stronger in midlife and older individuals than in younger individuals [12].

Therefore, the current study aimed to investigate the association of personality with BMI and obesity in a large Danish community sample of midlife men and women.

\section{Material and Methods}

\section{Study Sample}

This cross-sectional study is based on data from the Copenhagen Ageing and Midlife Biobank (CAMB). CAMB is a follow-up of members from three longitudinal cohorts [26], The Metropolit Study [27], The Copenhagen Perinatal Cohort [28], and The Danish Longitudinal Study on Work Unemployment and Health [29]. More than 5,500 participants aged 49-63 years of mainly Danish ethnicity (98\%) were assessed at this midlife follow-up resulting in a response rate of 30\%. By design the sex distributions of the three cohorts included in the CAMB sample differ. Thus, the Copenhagen perinatal cohort and the Danish Longitudinal Study on Work Unemployment and Health cohort include both men and women, while the Metropolit study cohort consists of men only.

Of the 5,576 participants 5,417 had complete data on sex, age, and years of education. Information about personality was missing for 131 of these participants. Thus, the final study sample comprised 5,286 participants of which 3,613 are men and 1,673 are women.

\section{Measures}

BMI

Height and weight were measured at a clinical examination [30]. BMI of the participants was calculated as weight $(\mathrm{kg})$ / height $(\mathrm{m})^{2}$, and BMI was used as a continuous outcome variable in the analyses of variance (ANOVA). For some of the logistic regression models, a binary variable was constructed that defined participants with a BMI $\geq 30 \mathrm{~kg} / \mathrm{m}^{2}$ as obese and participants with a $\mathrm{BMI}<30 \mathrm{~kg} / \mathrm{m}^{2}$ as non-obese.

Personality

The Danish version of the NEO Five-Factor Inventory (NEO-FFI) was used to evaluate the personality structure of the participants. The NEO-FFI comprises 60 questions and is a well-validated short version of the Revised NEO Personality Inventory (NEO PI-R) [14], which assesses the Big Five personality traits neurot- 
Wimmelmann et al:: Associations of Personality with Body Mass Index and Obesity in a Large Late Midlife Community Sample

icism, extraversion, openness, agreeableness, and conscientiousness. All 60 NEO-FFI items are answered on a five-point Likert scale from 0 'strongly agree' to 4 'strongly disagree', thus resulting in a 0-48 total score range for the 12 items included for each personality dimension. Cronbach's alpha for the five traits are reported to be $0.77-0.84$, reflecting a high internal consistency of the Danish version of the test [31]. The relation between personality and BMI was not linear for any of the five traits which is why personality trait scores were included as categorical variables with categories reflecting high, medium, and low scores based on the tertiles for each trait.

\section{Confounders}

Confounders and potential mediators were included based on previous literature and available information.

Education in Years

A continuous variable with information on 'duration of education' was derived from two categorical variables: school education and vocational training. Nine categories of school education were recoded to 8-12 years and seven categories of vocational training to 0-5 years, combined resulting in the applied 8-17 years scale of educational length. For a detailed description see Mortensen et al. [32].

\section{Potential Mediators (Health Behavior Factors)}

Fast Food Eating

A binary variable (healthy vs. unhealthy eaters) was constructed based on a question concerning the frequency of fast food eating defined as eating foods such as burgers, pizzas, hot dogs, shawarmas etc. Answers ranged from 1 (never) to 6 (every day). Healthy eaters were defined as participants eating fast food less than once a week.

\section{Leisure Time Physical Activity}

Leisure time physical activity was self-reported. Participants were asked which of the following four statements best described their general level of leisure time physical activity: hard exercise at elite level several times a week; exercise or heavy domestic work at least 4 hs a week; easy physical activity such as walking and cycling at least $4 \mathrm{~h}$ a week; or sedentary activity such as reading and television watching.

\section{Alcohol Consumption}

Participants reported their usual alcohol consumption in units for weekdays and weekends for different alcoholic beverages including beer, wine, spirits etc. The participants' total weekly (weekdays + weekends) alcohol consumption was calculated, and a categorical alcohol consumption variable was constructed based on the Danish national guidelines for alcohol consumption. Four categories were derived: 1 ( 0 units a week); 2 (1-21 units per week for men and 1-14 units per week for women); 3 (more than 21 units per week for men and more than 14 units a week for women) and 4 (more than 35 units per week).

\section{Smoking}

Smoking was self-reported, and a binary variable was constructed with participants who answered 'Yes, I smoke' or 'Yes, I smoke but not every day' categorized as 'smokers' and participants who answered 'No, but I have smoked previously' or 'No, I have never smoked' categorized as 'non-smokers'.

\section{Data Analysis}

Descriptive statistics were used to investigate participant characteristics, and differences between men and women were examined using chi-square tests or independent t-tests depending on the nature of the dependent variable.

Associations of personality with BMI were investigated in linear models and in logistic regression models using a binary obesity variable as outcome. Preliminary analyses showed a tendency towards an interaction effect of personality and sex on BMI. In line with previous studies, all analyses were therefore conducted separately for men and women. Preliminary analyses showed that age analyzed as a binary variable was not associated with BMI in either men or women and was therefore not included the main analyses. In contrast, duration of education was significantly associated with BMI in both men $(r=-0.19, p<$ $0.001)$ and women $(r=-0.14, p<0.001)$ and was therefore included in the main analyses. 
Wimmelmann et al.: Associations of Personality with Body Mass Index and Obesity in a Large Late Midlife Community Sample

Firstly, we investigated the association of each personality trait with BMI using analysis of variance (ANOVA) in an unadjusted model. Since, there is a number of relatively strong correlations among the five personality traits assessed by the NEO FFI in the CAMB sample [5], a second model was analyzed using multifactorial ANOVA, which included all five personality traits assessed by the NEO FFI. Finally, a model adjusting for duration of education in addition to the five personality traits was investigated using analysis of covariance (ANCOVA).

Secondly, we used logistic models to investigate associations of each personality trait with a binary obesity variable as outcome. Again, an unadjusted model and a fully adjusted model that included all five personality traits and duration of education was investigated. As underweight has been associated with psychological characteristics similar to that of obesity, including more mental distress [13], the logistic analyses were repeated excluding underweight participants $(\mathrm{N}=55)$. Thus, the sample used in the logistic analyses comprised 5,231 participants.

Finally, to investigate the potential mediating effect of health behavior, supplementary linear and logistic models were conducted adjusting for fast food eating behavior, physical activity, alcohol consumption, and smoking. Analyses were performed in a combined model including all five traits and duration of education.

\section{Results}

Table 1 presents participant characteristics including age, BMI, obesity, duration of education, level of physical activity, fast food eating, alcohol consumption, smoking, and personality for the total study sample and separately for men and women. The age range for the total CAMB sample was 49-63 years, with a subsample from the Danish Longitudinal Study on Work Unemployment and Health and the Copenhagen perinatal cohorts aged 49-53 years and a subsample aged 56-63 years from the Metropolit study and The Danish Longitudinal Study on Work Unemployment and Health cohorts. Of the total 5,286 participants, more than $15 \%$ had a BMI $>30 \mathrm{~kg} / \mathrm{m}^{2}$ and were therefore classified as obese. The mean duration of education was 13.2 years, with women having a significantly longer education than men. Almost $60 \%$ of the total sample described their general level of physical activity as easy activity at least $4 \mathrm{~h}$ a week, and $10 \%$ reported to mainly engage in sedentary activities. More than $13 \%$ of the total sample reported to eat fast food more than once a week. Furthermore, men and women differed significantly on all included characteristics except for prevalence of obesity. Thus, men had a higher mean BMI, were more likely to engage in hard or elite level physical activity, reported to eat fast food more frequently, reported shorter education, and had lower scores on all five personality traits compared with women. The size of the effect of sex on personality was small for all traits (from 0.06 standard deviation (SD) for extraversion to 0.44 SD for agreeableness).

Associations of personality with BMI are shown in table 2, and the results differed substantially between men and women. In the models including all five personality traits, extraversion was significantly associated with BMI in both men and women with higher, BMI among men and women scoring high on this trait. These associations remained significant after adjusting for duration of education. Significant negative associations of openness with BMI were observed among men and women in the model that included all traits. That is, higher BMI was observed among participants scoring low on openness. However, these associations became non-significant when including duration of education. Agreeableness was significantly associated with BMI in women with higher BMI observed among low scoring women, and these associations remained after adjusting for duration of education. In men, conscientiousness significantly predicted BMI in all models with higher BMI in the low scoring category, but this personality dimension did not predict BMI in women. Associations of neuroticism and BMI were non-significant for both men and women. 
Wimmelmann et al.: Associations of Personality with Body Mass Index and Obesity in a Large Late Midlife Community Sample

Table 1. Sample characteristics including age, BMI, obesity, duration of education, physical activity, fast food eating, alcohol consumption, smoking, and personality for the total sample and for men and women

\begin{tabular}{|c|c|c|c|c|}
\hline & Total & Men & Women & P value* \\
\hline $\mathrm{N}$ & 5,286 & 3,613 & 1,673 & \\
\hline Age, \% & & & & $<0.001$ \\
\hline 49-53 years & 42.8 & 26.6 & 77.8 & \\
\hline $56-63$ years & 57.2 & 73.4 & 22.2 & \\
\hline BMI, M (SD) & $26.1(4.2)$ & $26.5(3.9)$ & $25.3(4.8)$ & $<0.001$ \\
\hline Obesity (\%) & & & & 0.070 \\
\hline Obesity & 15.1 & 15.7 & 13.8 & \\
\hline Non-obesity & 84.9 & 84.3 & 86.2 & \\
\hline Education in years, M (SD) & $13.2(2.4)$ & $13.1(2.5)$ & $13.3(2.2)$ & 0.002 \\
\hline Physical activity, \% & & & & $<0.001$ \\
\hline Elite level & 2.3 & 2.8 & 1.2 & \\
\hline Hard work & 30.3 & 32.9 & 25.1 & \\
\hline Light work & 57.3 & 53.6 & 66.2 & \\
\hline Sedentary & 9.6 & 10.7 & 7.5 & \\
\hline Fast food eating, \% & & & & $<0.001$ \\
\hline >1 day/week & 13.5 & 16.0 & 7.9 & \\
\hline$\leq 1$ day/week & 86.5 & 84.0 & 92.1 & \\
\hline Alcohol consumption, $\%$ & & & & $<0.001$ \\
\hline Non-drinkers & 11.4 & 8.6 & 17.5 & \\
\hline Light drinkers & 70.9 & 71.2 & 70.1 & \\
\hline Drinkers & 13.3 & 14.1 & 11.7 & \\
\hline Heavy drinkers & 4.4 & 6.1 & 0.7 & \\
\hline Smoking, \% & & & & 0.617 \\
\hline Smoker & 23 & 23.2 & 22.5 & \\
\hline Non-smoker & 77 & 76.8 & 77.5 & \\
\hline \multicolumn{5}{|l|}{ Personality, M (SD) } \\
\hline Neuroticism & $17.6(7.1)$ & $16.8(7.0)$ & $19.3(7.2)$ & $<0.001$ \\
\hline Extraversion & $30.8(6.2)$ & 30.7 (6.2) & $31.1(6.3)$ & 0.019 \\
\hline Openness & $28.3(6.2)$ & $28.0(6.2)$ & $28.9(6.1)$ & $<0.001$ \\
\hline Agreeableness & $33.5(5.2)$ & $32.8(5.2)$ & $35.1(4.9)$ & $<0.001$ \\
\hline Conscientiousness & $33.6(5.5)$ & $33.6(5.5)$ & 33.7 (5.3) & 0.354 \\
\hline
\end{tabular}

$\mathrm{M}=$ mean; $\mathrm{SD}=$ standard deviation.

*P value of independent $t$-tests or chi-square tests of the difference between men and women depending on the nature of the dependent variable. Level of significance $p<0.05$.

Overall, significant associations between personality and BMI were weaker when investigating each personality trait separately. Also, associations of extraversion with BMI were non-significant in women in models including one trait at a time while these associations were significant when including all traits. In general, a higher BMI was observed among men scoring high on extraversion and low on openness and conscientiousness, whereas women 
Wimmelmann et al.: Associations of Personality with Body Mass Index and Obesity in a Large Late Midlife Community Sample

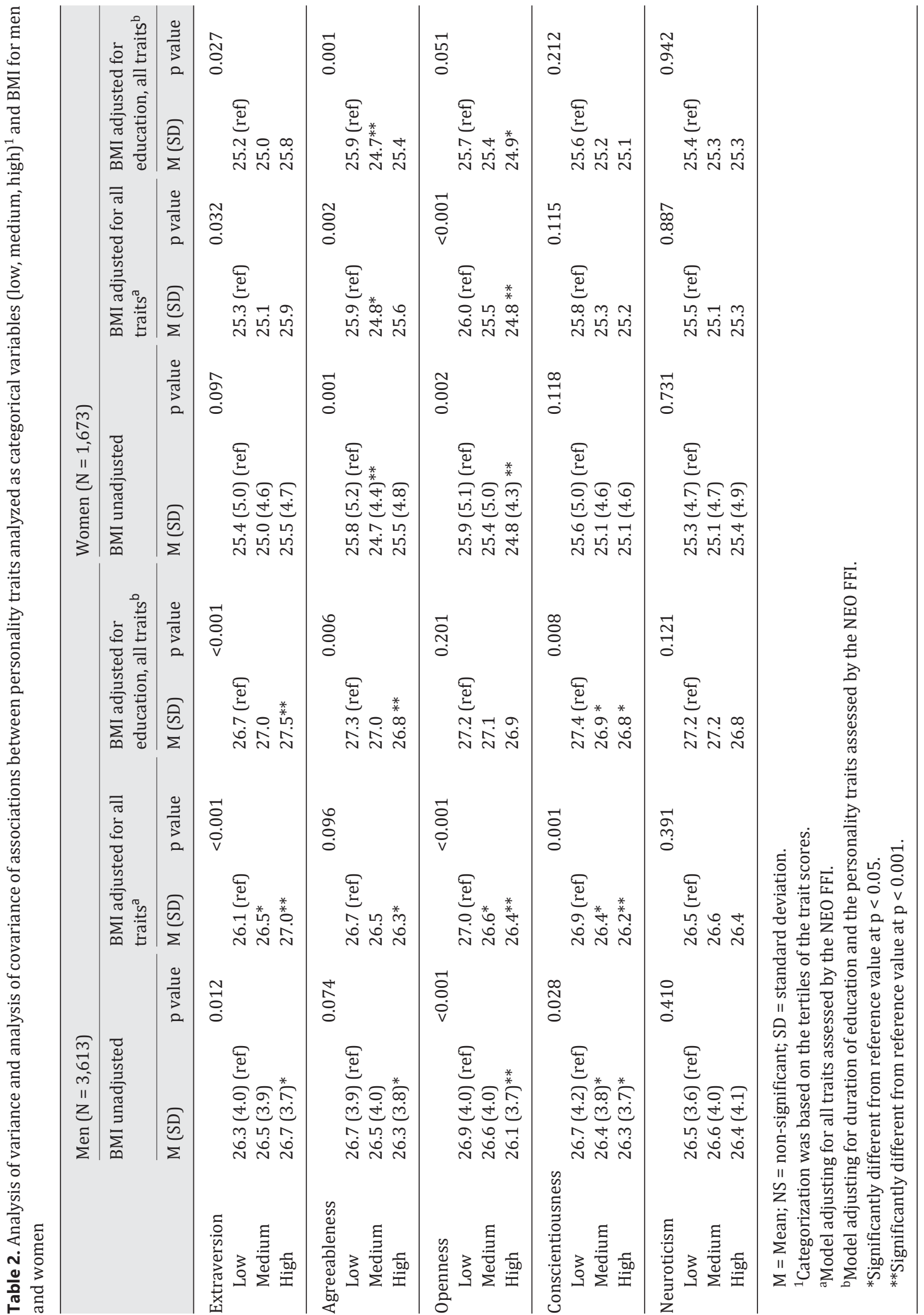


Wimmelmann et al.: Associations of Personality with Body Mass Index and Obesity in a Large Late Midlife Community Sample

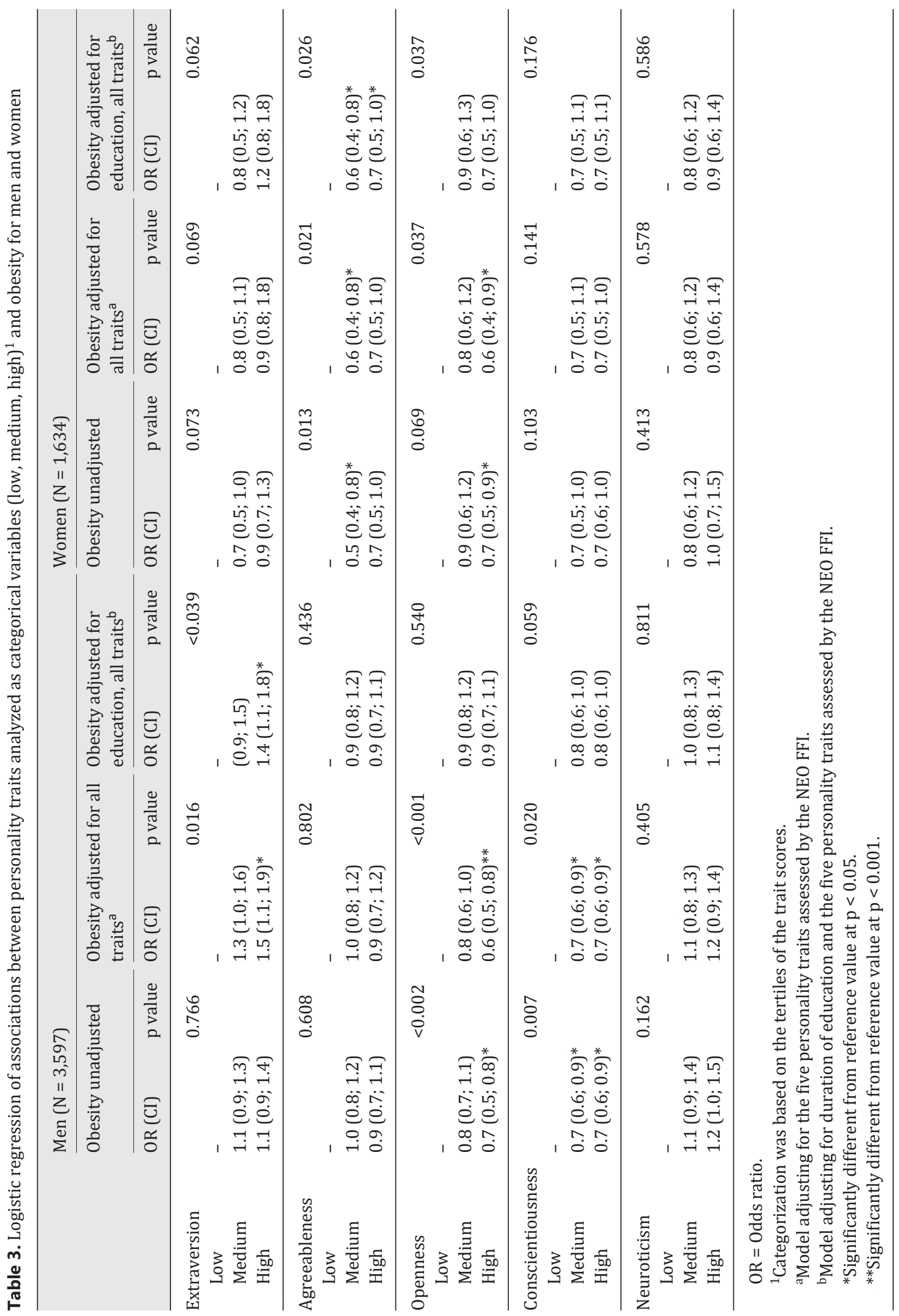


scoring low on openness and medium on agreeableness had a higher BMI. However, the size of these effects was relatively small. For instance, in the unadjusted model the difference in BMI between individuals scoring high versus low on openness was $0.13 \mathrm{SD}$ among men and 0.18 SD among women.

Associations between personality and obesity are presented in table 3. Results from the logistic analyses that excluded underweight participants did not differ from the analyses that included all participants. Therefore, only results of the logistic analyses that excluded underweight participants are presented here. In the model investigating all five personality traits, extraversion, openness, and conscientiousness significantly predicted obesity in men with high scores on extraversion and low scores on openness and conscientiousness increasing the odds of being obese. However, only extraversion predicted obesity in men after adjusting for education. In women, openness and agreeableness significantly predicted obesity with low scores on these traits increasing the odds of obesity. While the association of openness with obesity became non-significant, agreeableness remained a significant predictor when adjusting for duration of education. Thus, women with a low agreeableness score had $40 \%$ higher odds of being obese than women in the medium score group and 30\% increased odds of being obese compared with women scoring high on agreeableness independently of duration of education. These odds ratios suggest the lowest risk of obesity in medium score group who also had the lowest mean BMI (table 3).

Neuroticism was not associated with obesity in any of the analyses.

In the analyses that investigated each personality trait separately, openness and conscientiousness were significantly associated with obesity in men, and only agreeableness was associated with obesity in women.

\section{Supplementary Analyses}

The supplementary linear analyses investigating the effect of health behavior showed that extraversion $(p<0.001)$, agreeableness $(p=0.011)$, and conscientiousness $(p=0.028)$ remained significantly associated with BMI among men after adjusting for fast food eating, alcohol consumption, smoking, and physical activity in addition to duration of education, while this was the case for extraversion $(p=0.009)$ and agreeableness $(p=0.009)$ among women. Thus, this analysis presents some evidence that the observed associations of extraversion, agreeableness, and conscientiousness with BMI are partly independent of the included health behavior factors.

In the supplementary logistics analyses extraversion remained significantly associated with obesity among both men $(p=0.004)$ and women $(p=0.029)$ after adjusting for the selected health behaviors and education with men and women scoring high on extraversion having 1.6 and 1.5 higher odds of obesity than their low scoring counterparts, respectively. Thus, the analyses provide evidence of an effect of this personality trait, which is independent of the included health behavior factors.

\section{Discussion}

Results of the current study indicated that some personality traits assessed by the NEO FFI were associated with BMI and to a lesser extent with obesity. Also, personality-BMI and personality-obesity associations differed substantially between men and women. In general, personality was more strongly associated with BMI and especially obesity in men than in women possibly reflecting a power problem with women constituting less than one-third of the sample. 
Wimmelmann et al.: Associations of Personality with Body Mass Index and Obesity in a Large Late Midlife Community Sample

When interpreting the findings, it is important to note the difference between linear analyses of BMI and logistic analyses of obesity. Linear analyses of BMI are primarily influenced by weight variation within the normal range while the logistic analyses focus on prediction of obesity vs. normal weight and overweight. Obviously, the same factors may not determine normal-weight variation and obesity.

\section{Extraversion}

Extraversion was the main predictor of BMI in men, and the findings suggest a stronger association of extraversion with normal-weight variation than with obesity.

In general, these results are in line with most previous research. While Sutin et al. [12] found negative associations of extraversion with BMI in women and no association with BMI in men, several other population-based studies investigating personality and BMI have reported extraversion to be positively associated with BMI in men and unrelated to BMI in women $[8,16,21,24]$.

These somewhat mixed results may reflect that different aspects of the personality dimension extraversion contribute to low and high BMI [12]. For instance, it has been indicated that 'sensitivity to reward', a feature of extraversion related to an appetitive-positive affect system [33], is positively associated with overweight $[8,33]$, whereas subfacets of extraversion such as being active and outgoing may be negatively related to BMI. In relation to BMI, the importance of the different subfacets may depend on the age of the sample. This may explain why studies with younger samples have reported negative associations between extraversion and BMI and obesity [12] while positive associations between extraversion and BMI/obesity have been found among men in the present study and in previous studies with midlife and older samples [16, 21,24], suggesting a cumulative effect of extraversion on BMI through the adult lifespan. This may reflect that men high on extraversion are more outgoing and more likely to participate in social events that often include food and drinks. They may worry less about weight and calorie consumption and therefore are more likely to experience a gradual increase in their BMI as they grow older. In extroverted women, BMI changes through the lifespan may be influenced by several other factors such as pregnancy, menopause, and perhaps greater weight consciousness. However, further research investigating the potential mechanisms underlying the association between extraversion and BMI and obesity is highly needed.

\section{Agreeableness}

Agreeableness was associated with BMI in both women and men and with obesity in women independently of duration of education. Interestingly, women with medium scores had the lowest BMI and the lowest odds of being obese, suggesting a non-linear relation between agreeableness and BMI/obesity in women.

In contrast, a recent meta-analysis [16], comprising 78,931 participants from nine cohort studies with a mean age of 50 years, concluded that agreeableness was not significantly associated with obesity. Others have reported that higher obesity prevalence was associated with higher agreeableness score in men, but not in women [34], independently of socioeconomic status in adulthood [23]. Thus, results of the current study are contrasting earlier findings with regard to the relation of agreeableness and BMI and obesity. Provencher et al. [35] found very elevated agreeableness scores among 154 overweight women and women with obesity with a mean age of 42.4 years compared with a standard reference group of women [14], but higher level of agreeableness predicted lower score on susceptibility to hunger. Thus, it could be speculated that susceptibility to hunger and inappropriate eating behavior contribute to the higher BMI and the higher prevalence of obesity among women scoring low on agreeableness observed in the current study. 
Wimmelmann et al.: Associations of Personality with Body Mass Index and Obesity in a Large Late Midlife Community Sample

\section{Openness}

The unadjusted analyses that included all personality traits showed significant (inverse) associations with BMI and obesity in both men and women. However, in the models adjusting for duration of education, these associations became non-significant.

Historically, the personality trait of openness has been linked to intelligence [9], and positive associations between this personality dimension and cognitive ability in the CAMB sample have been reported elsewhere [32]. Furthermore, intelligence has consistently been associated with health outcomes, possibly because intelligence reflects knowledge, reasoning and problem-solving skills that are useful in engaging in a healthy lifestyle and in preventing unhealthy conditions and chronic disease [36]. For instance, two Danish longitudinal studies of 1,790 [37] and 6,292 men [38] both reported that low intelligence and low educational level were associated with subsequent BMI changes and the risk of developing obesity. In the present study, individuals high on openness had on average 2.04 years longer education than individuals low on openness (data not shown). Thus, results of the present study suggest that duration of education may partly explain the relation between openness and BMI/obesity.

\section{Conscientiousness}

Conscientiousness was negatively associated with BMI in men, but not in women, and in men the association with obesity was significant in the unadjusted analyses and in the analyses adjusting for all five personality traits. Estimates for BMI and obesity were similar for men and women in our study, suggesting that the non-significant associations in women reflect power problems. This assumption is consistent with a recent meta-analysis [16] of associations of personality and obesity reporting that across 78,931 individuals, those with high conscientiousness had almost $40 \%$ lower odds of being obese compared with individuals low on this personality dimension. However, in the current study associations of conscientiousness with risk of obesity became non-significant in adjusted models including duration of education. Individuals high on conscientiousness are typically characterized by being organized and self-disciplined [14], and it has been suggested that they therefore are more likely to follow a healthy diet and engage in health behaviors in general $[12,17]$. In the present study men with high scores on conscientiousness had longer education compared with men in the low conscientiousness group ( 13.5 vs. 12.7 years; $p<0.001$ ), were less likely to eat fast food every week ( $14.5 \%$ vs. $19.5 \%$ fast food eaters; $p=0.001)$, less likely to smoke ( $17 \%$ vs. $31.1 \%$; p < 0.001 ), and reported a higher level of physical activity ( $31.6 \%$ vs. $21.0 \%$ engaging in hard work or elite level exercise; $p<0.001$ ) and a lower level of alcohol consumption $(3.8 \%$ vs. $9.2 \%$ categorized as heavy drinker; $p<0.001)$. Thus, in line with existing reports [12] showing that behavioral factors account for about $50 \%$ of the association between conscientiousness and BMI, results of the current study suggest that conscientiousness primarily contribute to obesity through health behaviors including eating and drinking habits, physical activity, and smoking. However, conscientiousness remained a significant predictor of BMI $(p=0.028)$ and obesity $(p=0.037)$ in analyses adjusting for all five personality traits in addition to duration of education and the selected health behavior factors.

\section{Neuroticism}

Finally, there was no evidence for associations between the personality trait neuroticism and BMI as well as obesity. That is, neuroticism was not a significant predictor of BMI or obesity in either men or women. This is contrasting earlier studies reporting significant positive associations between neuroticism and BMI $[8,11]$. There is some evidence that neuroticism scores are lower in midlife than in younger and older ages [39] possibly explaining why neuroticism was not associated with BMI or obesity in the current study. Also, the CAMB 
Wimmelmann et al.: Associations of Personality with Body Mass Index and Obesity in a Large Late Midlife Community Sample

study had a relatively modest response rate of $30 \%$, possibly reflecting a selection bias, which should be considered when interpreting the results. For instance, it is likely that participants and non-participants differ on certain individual factors, with participants being more resourceful, having less mental distress, longer education, and better health than non-participants. Future research should therefore further investigate the neuroticism-BMI relation in individuals from the community.

\section{Strengths and Limitations}

This study has several strengths including a large community-based sample of individuals in late midlife, objectively measured weight and height, and detailed information about personality, sociodemographic factors, and health behavior. Yet, some limitations should be mentioned.

Firstly, the cross-sectional design limits the interpretation of the results with regard to causality. That is, the direction of the relationship between personality and obesity could not be inferred from the current data. However, personality is assumed to be relatively stable from early adulthood [14], and in general longitudinal research has suggested that personality influences outcomes related to health behavior including BMI and obesity across the adult lifespan [11].

Secondly, by design there is very little age variation within the CAMB sample. Age has previously been found to be one of the most consistent predictors of overweight and obesity with middle-aged and older individuals in higher risk of being obese than their younger counterparts [40, 41]. Members of the CAMB sample are all 49-63 years of age, and thus results of the present study are restricted to midlife individuals. Furthermore, cultural differences may affect public and individual perspectives on obesity [42], and it is therefore uncertain whether the current results can be generalized beyond the Danish population.

Finally, duration of education was, in line with other studies [16], analyzed as a confounder. However, in the current study some personality traits, especially openness and conscientiousness, were positively associated with duration of education indicating that personality may influence education, thus being a mediator. In this perspective, controlling for duration of education may be problematic which is why the primary focus of the current study is on the model not including duration of education. Also, information on health behavior, including physical activity, fast food eating, smoking and alcohol consumption, was self-reported. It has been suggested that especially overweight individuals and individuals with obesity tend to over-report health-promoting behaviors while under-reporting health behaviors detrimental to health. Thus, the influence of health behavior on the personality-BMI/obesity relation in the current study may be influenced by such reporting bias reducing the actual effect of these behaviors. On the other hand, self-reported fast food eating is most likely an insufficient indicator of food intake patterns, and a more complete measure of food intake might explain more variance.

\section{Conclusions}

Despite these limitations, the results of the present study suggest that personality is significantly associated with BMI and to a lesser extent with obesity. High extraversion and low openness were associated with a higher BMI in both men and women while low conscientiousness and low agreeableness were also significantly associated with a higher BMI in men and women respectively. Generally, these associations were relatively weak, and the 
Wimmelmann et al.: Associations of Personality with Body Mass Index and Obesity in a Large Late Midlife Community Sample

only personality traits that were significantly associated with risk of obesity when adjusting for duration of education were extraversion (high scores) in men and agreeableness (low scores) in women. Some of the observed differences in associations between analyses of BMI and analyses of obesity and between associations for men and women may reflect the associated statistical power problems.

Finally, the current study addressed the question of whether to analyze personality traits separately or whether to consider the significant inter-correlations among the five personality traits [5] and include them in the same model. In general, the personality-BMI/ obesity associations in this study became stronger in models adjusting for all five personality traits. Future studies should consider the interrelations of the different personality traits when investigating associations of personality and health outcome such as BMI and obesity.

\section{Acknowledgments}

The Copenhagen Aging and Midlife Biobank has been supported by a generous grant from the VELUX FOUNDATION. Authors thank the staff at Institute of Public Health and the National Research Center for the Working Environment who undertook the data collection. Further thanks to Kirsten Avlund, Helle Bruunsgaard, Nils- Erik Fiehn, Åse Marie Hansen, Poul Holm-Pedersen, Rikke Lund, Erik Lykke Mortensen, and Merete Osler who initiated and established the Copenhagen Aging and Midlife Biobank from 2009 to 2011. The authors acknowledge the crucial role of the initiators and steering groups of the Metropolit Cohort, The Copenhagen Perinatal Cohort, and The Danish Longitudinal Study on Work Unemployment and Health.

\section{Ethics, Consent, and Permissions}

The three cohorts included in CAMB have all been approved by the local committees for research ethics. Furthermore, the local committee for research ethics has approved CAMB as a combined database for the three cohorts.

Participants received both oral and written information on the study before assessment, and all participants were required to give both oral and written consent to participate.

\section{Author Contributions}

CLW conducted the data analyses and prepared the manuscript. RL, UC, TFM, MO, and ELM made substantial contributions to the data collection, the study design, and/or manuscript revisions. All authors have read and approved the final version of the manuscript.

\section{Disclosure Statement}

Nothing to disclose. 
Wimmelmann et al.: Associations of Personality with Body Mass Index and Obesity in a Large Late Midlife Community Sample

\section{References}

1 Bray GA: Medical consequences of obesity. J Clin Endocrinol Metab 2004;89:2583-2589.

2 World Health Organization: Chapter. 7:Target 7 - Halt the rise in diabetes and obesity: in Global Status Report on Noncommunicable Diseases. Geneva World Health Organization, 2014, pp. 79-94. http://apps.who.int/iris/ bitstream/10665/148114/1/9789241564854_eng.pdf?ua=1 (last accessed March 29, 2018).

- 3 Lim SS, Vos T, Flaxman AD, Danaei G, Shibuya K, Adair-Rohani H: A comparative risk assessment of burden of disease and injury attributable to 67 risk factors and risk factor clusters in 21 regions, 1990-2010: a systematic analysis for the Global Burden of Disease Study 2010. Lancet 2013;380:2224-2260.

4 Ng M, Fleming T, Robinson M, Thomson B, Graetz N, Margono C, Mullany EC, Biryukov S, Abbafati C, Abera SF, Abraham JP, Abu-Rmeileh NM, Achoki T, AlBuhairan FS, Alemu ZA, Alfonso R, Ali MK, Ali R, Guzman NA, Ammar W, Anwari P, Banerjee A, Barquera S, Basu S, Bennett DA, Bhutta Z, Blore J, Cabral N, Nonato IC, Chang JC, Chowdhury R, Courville KJ, Criqui MH, Cundiff DK, Dabhadkar KC, Dandona L, Davis A, Dayama A, Dharmaratne SD, Ding EL, Durrani AM, Esteghamati A, Farzadfar F, Fay DF, Feigin VL, Flaxman A, Forouzanfar MH, Goto A, Green MA, Gupta R, Hafezi-Nejad N, Hankey GJ, Harewood HC, Havmoeller R, Hay S, Hernandez L, Husseini A, Idrisov BT, Ikeda N, Islami F, Jahangir E, Jassal SK, Jee SH, Jeffreys M, Jonas JB, Kabagambe EK, Khalifa SE, Kengne AP, Khader YS, Khang YH, Kim D, Kimokoti RW, Kinge JM, Kokubo Y, Kosen S, Kwan G, Lai T, Leinsalu M, Li Y, Liang X, Liu S, Logroscino G, Lotufo PA, Lu Y, Ma J, Mainoo NK, Mensah GA, Merriman TR, Mokdad AH, Moschandreas J, Naghavi M, Naheed A, Nand D, Narayan KM, Nelson EL, Neuhouser ML, Nisar MI, Ohkubo T, Oti SO, Pedroza A, Prabhakaran D, Roy N, Sampson U, Seo H, Sepanlou SG, Shibuya K, Shiri R, Shiue I, Singh GM, Singh JA, Skirbekk V, Stapelberg NJ, Sturua L, Sykes BL, Tobias M, Tran BX, Trasande L, Toyoshima H, van de Vijver S, Vasankari TJ, Veerman JL, Velasquez-Melendez G, Vlassov VV, Vollset SE, Vos T, Wang C, Wang X, Weiderpass E, Werdecker A, Wright JL, Yang YC, Yatsuya H, Yoon J, Yoon SJ, Zhao Y, Zhou M, Zhu S, Lopez AD, Murray CJ, Gakidou E: Global, regional, and national prevalence of overweight and obesity in children and adults during 1980-2013: a systematic analysis for the Global Burden of Disease Study 2013. Lancet 2014;384:766-781.

5 Mortensen EL, Flensborg-Madsen T, Molbo D, Christensen U, Osler M, Avlund K, Lund R: Personality in late midlife: associations with demographic factors and cognitive ability. J Aging Health 2014;26:21-36.

-6 Evers C, Stok F, de Ridder DTD: Feeding your feelings: Emotion regulation strategies and emotional eating. Pers Soc Psychol Bull 2010;36:792-804.

7 Hoyt AL, Rhodes RE, Hausenblas HA, Giacobbi PR Jr: Integrating five-factor model facet-level traits with the theory of planned behavior and exercise. Psychol Sport Exerc 2009:10:565-572.

8 Gerlach G, Herpertz S, Loeber S: Personality traits and obesity: a systematic review. Obes Rev 2015;16:32-63. Digman JM: Personality structure: emergence of the five factor model. Annu Rev Psychol 1990;41:417-440. Lahey BB: Public health significance of neuroticism. Am Psychol 2009;64:241.

10 Sutin AR, Ferrucci L, Zonderman AB, Terracciano A: Personality and obesity across the adult life span. J Pers Soc Psychol 2011;101:579-592.

12 Sutin AR, Terracciano A: Personality traits and body mass index: modifiers and mechanisms. Psychol Health 2016;31:259-275.

13 De Wit LM, Van Straten A, Van Herten M, Penninx BW, Cuijpers P: Depression and body mass index, a u-shaped association. BMC Public Health 2009;9:14.

14 Costa PT, McCrae RR: Normal personality assessment in clinical practice: the NEO Personality Inventory. Psychol Assess 1992;4:5.

15 Terracciano A, Sutin AR, McCrae RR, Deiana B, Ferrucci L, Schlessinger D: Facets of personality linked to underweight and overweight. Psychosom Med 2009;71:682.

16 Jokela M, Hintsanen M, Hakulinen C, Batty GD, Nabi H, Singh-Manoux A, Kivimäki M: Association of personality with the development and persistence of obesity: a meta-analysis based on individual-participant data. Obesi Rev 2013;14:315-323.

17 Hagger-Johnson GE, Whiteman MC: Conscientiousness facets and health behaviors: a latent variable modeling approach. Pers Individ Di 2007; 43:1235-1245.

18 Rhodes RE, Smith NEI: Personality correlates of physical activity: a review and meta-analysis. Br J Sports Med 2006;40:958-965.

19 Keller C, Siegrist M: Does personality influence eating styles and food choices? Direct and indirect effects. Appetite 2015;84:128-138.

20 Ellickson-Larew S, Naragon-Gainey K, Watson D: Pathological eating behaviors, BMI, and facet-level traits: the roles of conscientiousness, neuroticism, and impulsivity. Eat Behav 2013;14:428-431.

21 Kakizaki M, Kuriyama S, Sato Y, Shimazu T, Matsuda-Ohmori K, Nakaya N: Personality and body mass index: a cross-sectional analysis from the Miyagi Cohort Study. J Psychosom Res 2008;64:71-80.

-22 Abilés V, Rodríguez-Ruiz S, Abilés J, Mellado C, García A, de la Cruz AP, Fernández-Santaella MC: Psychological characteristics of morbidly obese candidates for bariatric surgery. Obesi Surg 2010;20:161-167.

-23 Chapman BP, Fiscella K, Duberstein P, Coletta M, Kawachi I: Can the influence of childhood socioeconomic status on men's and women's adult body mass be explained by adult socioeconomic status or personality? Findings from a national sample. Health Psychol 2009;28:419.

-24 Brummett BH, Babyak MA, Williams RB, Barefoot JC, Costa PT, Siegler IC: NEO personality domains and gender predict levels and trends in body mass index over 14 years during midlife. J Res Pers 2006;40:222-236. 
Wimmelmann et al.: Associations of Personality with Body Mass Index and Obesity in a Large Late Midlife Community Sample

25

$-26$

Avlund K, Osler M, Mortensen EL, Christensen U, Bruunsgaard H, Holm-Pedersen P, Fiehn NE, Hansen AM, Bachkati SH, Meincke RH, Jepsen E, Molbo D, Lund R: Copenhagen Aging and Midlife Biobank (CAMB). An introduction. J Aging Health 2014;26:5-20.

-27 Osler M, Lund R, Kriegbaum M, Christensen U, Nybo Andersen A-M: Cohort profile: The Metropolit 1953 Danish male birth cohort. Int J Epidemiol 2006;35:541-545.

28 Zachau-Christiansen B: The Influence of Prenatal and Perinatal Factors on Development during the First Year of Life. Helsinore, Poul A. Andersens Forlag, 1972.

29 Christensen U, Lund R, Damsgaard MT, Holstein BE, Ditlevsen S, Diderichsen F, Due P, Iversen L, Lynch J: Cynical hostility, socioeconomic position, health behaviors, and symptom load: a cross-sectional analysis in a Danish population-based study. Psychosom Med 2004;66:572-577.

-30 Hansen ÅM, Andersen LL, Skotte J, Christensen U, Mortensen OS, Molbo D, Lund R, Nilsson CJ, Avlund K: Social class differences in midlife physical performance. J Aging Health 2014;26:88-105.

31 Skovdahl-Hansen H, Mortensen EL, Scioetz H: Dokumentation for den danske udgave af NEO PI-R og NEO PI-R Kort Version. . Copenhagen, Dansk Psykologisk Forlag, 2004.

-32 Mortensen EL, Flensborg-Madsen T, Molbo D, Fagerlund B, Christensen U, Lund R, Osler M, Avlund K: The relationship between cognitive ability and demographic factors in late midlife. J Aging Health 2014;26:26-37.

-33 Davis C, Fox J: Sensitivity to reward and body mass index (BMI): evidence for a non-linear relationship. Appetite 2008;50:43-49.

-34 McCann SJ: Personality and American state differences in obesity prevalence. J Psychol 2011;145(5):419-433.

35 Provencher V, Bégin C, Gagnon-Girouard MP, Tremblay A, Boivin S, Lemieux S: Personality traits in overweight and obese women: associations with BMI and eating behaviors. Eat Behav 2008;9:294-302.

-36 Gottfredson LS, Deary IJ: Intelligence predicts health and longevity, but why? Curr Dir Psychol Sci 2004;13: $1-4$.

-37 Halkjær J, Holst C, Sørensen TI: Intelligence test score and educational level in relation to BMI changes and obesity. Obes Res2003;11:1238-1245.

-38 Larsen AM, Lund R, Kriegbaum M, Avlund K, Osler M: Childhood social circumstances and body mass index in adult life :the Metropolit 1953 Danish male birth cohort. Scandi J Public Health 2011;39:296-302.

-39 Steunenberg B, Twisk JW, Beekman AT, Deeg DJ, Kerkhof AJ: Stability and change of neuroticism in aging. J Gerontol B Psychol Sci Soc Sci 2005;60:P27-33.

-40 Ogden CL, Johnson CL, Carroll MD, Curtin LR, Flegal KM: Prevalence of overweight and obesity among US children, adolescents, and adults, 1999-2002. JAMA 2004;291:2847-2850.

41 Ogden CL, Carroll MD, Curtin LR, McDowell MA, Tabak CJ, Flegal KM: Prevalence of overweight and obesity in the United States, 1999-2004. JAMA 2006;295:1549-1555.

-42 Friedman KE, Reichmann SK, Costanzo PR, Zelli A, Ashmore JA, Musante GJ: Weight stigmatization and ideological beliefs: relation to psychological functioning in obese adults. Obes Res 2005;13:907-916. 